\title{
reciamuc
}

Revista cientifica de investigación actualización del mundo de las ciencias

\author{
Ingrid Lissette Salas Hurtado ${ }^{\text {a; }}$ Gustavo Luis Campi Rivera ${ }^{\text {b; }}$ Margarita Cristina

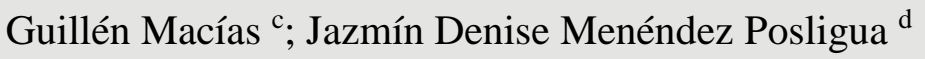

La ciencia de la biotecnología y sus aplicaciones

The science of biotechnology and its applications

Revista Científica de Investigación actualización del mundo de las Ciencias. Vol. 3 núm., 3, julio, ISSN: 2588-0748, 2018, pp. 902-920

DOI: $10.26820 /$ reciamuc/3.(3).julio.2019.902-920

\section{URL: http://reciamuc.com/index.php/RECIAMUC/article/view/309}

Código UNESCO: 2414.04 Bacteriología

Tipo de Investigación: Artículo de Revisión

(C) RECIAMUC; Editorial Saberes del Conocimiento, 2019

Recibido: 28/04/2019

Aceptado: 19/05/2019

Publicado: 01/07/2019

Correspondencia: $\underline{\text { dirgni82@yahoo.es }}$

a. Magister en Seguridad Higiene Industrial y Salud Ocupacional; Medico; Investigador Independiente; Guayaquil, Ecuador; dirgni82@yahoo.es

b. Médico; Investigador Independiente; Guayaquil, Ecuador; gcampiczs5@gmail.com

c. Médico; Investigador Independiente; Guayaquil, Ecuador; margaritaguillen17@yahoo.es

d. Magister en Gerencia de Servicios de Salud; Diploma Superior en Gestión de Desarrollo de los Servicios de Salud; Médico; Investigador Independiente; Guayaquil, Ecuador; jazmin.menendez81@ outlook.com 


\section{La ciencia de la biotecnología y sus aplicaciones}

Vol. 3, núm. 3., (2019)

Ingrid Lissette Salas Hurtado; Gustavo Luis Campi Rivera; Margarita Cristina Guillén Macías;

Jazmín Denise Menéndez Posligua

\section{RESUMEN}

Las aplicaciones y ventajas de la biotecnología son tan amplias y a su vez convincente, que prácticamente todas las industrias está utilizando esta tecnología. Los desarrollos están en marcha en áreas tan diversas como productos farmacéuticos, diagnósticos, los textiles, la acuicultura, la silvicultura, productos químicos, productos del hogar, limpieza del medio ambiente, procesamiento de alimentos, la medicina forense, entre muchos otros. La biotecnología está permitiendo a estas industrias hacer productos nuevos o mejores, con mayor rapidez, eficiencia y flexibilidad. Es una promesa significativa para el futuro aunque cierto riesgo está asociado a cualquier área, por lo que, esta ciencia debe seguir cuidadosamente lo regulado para asegurar los máximos beneficios con el menor riesgo. Sin embargo, su aplicación aún está en una encrucijada en cuanto a la aceptación del público, muchas organizaciones de estado no han formado una opinión sólida sobre este complejo tema. Los acontecimientos internacionales en los próximos años, sin duda, tendrán una gran influencia sobre la viabilidad a largo plazo de la biotecnología. El futuro de la oferta mundial de alimentos depende de qué tan bien los científicos, el gobierno y la comida industrial serán capaces de abastecer a los consumidores y de brindar los beneficios necesarios a través de la seguridad de la tecnología.

Palabras Claves: Biotecnología; Ciencia; Tecnología; Usos; Aplicaciones. 


\title{
La ciencia de la biotecnología y sus aplicaciones
}

Vol. 3, núm. 3., (2019)

Ingrid Lissette Salas Hurtado; Gustavo Luis Campi Rivera; Margarita Cristina Guillén Macías; Jazmín Denise Menéndez Posligua

\begin{abstract}
The applications and advantages of biotechnology are so broad and at the same time convincing, that practically every industry is using this technology. Developments are underway in areas as diverse as pharmaceuticals, diagnostics, textiles, aquaculture, forestry, chemicals, household products, environmental cleaning, food processing, and forensic medicine, among many others. Biotechnology is enabling these industries to make new or better products, with greater speed, efficiency and flexibility. It is a significant promise for the future although some risk is associated to any area, so, this science must carefully follow what is regulated to ensure the maximum benefits with the least risk. However, its application is still at a crossroads in terms of public acceptance, many state organizations have not formed a solid opinion on this complex issue. International events in the coming years will undoubtedly have a great influence on the long-term viability of biotechnology. The future of the global food supply depends on how well scientists, government and industrial food will be able to supply consumers and provide the necessary benefits through the security of technology.
\end{abstract}

Key Words: Biotechnology; Science; Technology; Applications; Applications. 


\section{La ciencia de la biotecnología y sus aplicaciones}

Vol. 3, núm. 3., (2019)

Ingrid Lissette Salas Hurtado; Gustavo Luis Campi Rivera; Margarita Cristina Guillén Macías;

Jazmín Denise Menéndez Posligua

\section{Introducción.}

Contrariamente a su nombre, la biotecnología no es una sola tecnología. Más bien es un grupo de tecnologías que comparten dos características comunes que trabajan con células vivas y sus moléculas y que tienen una amplia gama de usos prácticos que pueden ofrecer mejoras en la vida cotidiana.

La biotecnología puede definirse en términos generales como el uso de organismos o sus productos para fines comerciales. Como tal la biotecnología ha sido empleada durante años, se ha utilizado para hornear pan, para preparar bebidas alcohólicas, y en los cultivos de alimentos o animales domésticos (Laya, 2016). Pero los acontecimientos recientes en la biología molecular han dado a la biotecnología un nuevo significado, una nueva importancia, y un nuevo potencial, siendo la parte moderna de la biotecnología la que ha capturado la atención del público teniendo a su vez un efecto dramático en la economía y la sociedad mundo.

En un estudio realizado por (Horizons., 2018) el autor expone un ejemplo de la biotecnología moderna como lo es la ingeniería genética. La ingeniería genética es el proceso de transferencia de genes individuales entre los organismos o modificar los genes en un organismo para eliminar o añadir un rasgo o característica deseada. A través de la ingeniería genética, se forman los cultivos $\mathrm{u}$ organismos genéticamente modificados. Estos cultivos modificados genéticamente o transgénicos se utilizan para producir alimentos procedentes de la biotecnología. Es este tipo específico de la biotecnología moderna, parece generar la mayor atención y preocupación por los consumidores y grupos de consumidores. Lo que es interesante es que la 


\section{La ciencia de la biotecnología y sus aplicaciones}

Vol. 3, núm. 3., (2019)

Ingrid Lissette Salas Hurtado; Gustavo Luis Campi Rivera; Margarita Cristina Guillén Macías; Jazmín Denise Menéndez Posligua

biotecnología moderna es mucho más precisa que las formas tradicionales de la biotecnología y así es considerado por algunos como mucho más seguro.

La biotecnología moderna ha ofrecido oportunidades para producir alimentos más nutritivos y de mejor sabor, rendimiento de los cultivos y las plantas que están protegidas de forma natural de las enfermedades y los insectos. La biotecnología moderna permite la transferencia de sólo uno o unos pocos genes deseables, permitiendo de este modo a los científicos a desarrollar cultivos con rasgos beneficiosos específicos y reducir rasgos indeseables (Paña, 2015). La biotecnología tradicional, tal como la polinización cruzada en maíz produce numerosos cambios, las modificaciones genéticas han producido frutos que pueden madurar en la planta para mejorar el sabor, sin embargo, tienen mayor duración en almacén a través de la degradación de la pectina retardada. Los tomates y otros productos que contienen mayores niveles de ciertos nutrientes, como la vitamina $\mathrm{C}$, la vitamina $\mathrm{E}$ y beta caroteno, ayuda a proteger contra el riesgo de enfermedades crónicas, tales como algunos tipos de cáncer y enfermedades del corazón. (Paña, 2015).

La técnica de introducir el mismo modo de genes que aumentan tres veces más los niveles de hierro disponibles en el arroz es un remedio potencial para la deficiencia de hierro, una condición que causa anemia en más de mil millones de personas (Ramos, 2012). La aplicación de la biotecnología también es empleada en los lácteos la mayoría de los quesos duros de hoy en día están hechos con una enzima llamada renina biotecnología

La biotecnología moderna ofrece técnicas eficaces para hacer frente a los problemas de seguridad alimentaria. Los métodos biotécnicos pueden utilizarse para disminuir el tiempo 


\section{La ciencia de la biotecnología y sus aplicaciones}

Vol. 3, núm. 3., (2019)

Ingrid Lissette Salas Hurtado; Gustavo Luis Campi Rivera; Margarita Cristina Guillén Macías; Jazmín Denise Menéndez Posligua

necesario para detectar patógenos transmitidos por alimentos, toxinas y contaminantes químicos, así como para aumentar la sensibilidad de detección. Las enzimas, anticuerpos, y microorganismos producidos utilizando técnicas de $\mathrm{ADNr}$ se utilizan para controlar los sistemas de producción y de procesamiento de alimentos para el control de calidad (Duarte, 2010)

En resumen, la biotecnología moderna ofrece oportunidades para mejorar la calidad del producto, contenido nutricional y beneficios económicos. La composición genética de plantas y animales puede ser modificada por cualquiera con la inserción de nuevos genes útiles o eliminación de los no deseados. La biotecnología está cambiando la forma en que se cultivan las plantas y animales, aumentando su valor para los productores, procesadores, y los consumidores. Por tal motivo el objetivo de este trabajo investigativo es dar a conocer las aplicaciones que ofrece esta ciencia.

\section{Métodos y materiales.}

Para el desarrollo de este proceso investigativo, se plantea como metodología la encaminada hacia una orientación científica particular que se encuentra determinada por la necesidad de indagar en forma precisa y coherente una situación, en tal sentido (Davila, 2015) define la metodología "como aquellos pasos previos que son seleccionados por el investigador para lograr resultados favorables que le ayuden a plantear nuevas ideas”. (p.66)

Lo citado por el autor, lleva a entender que el desarrollo de la acción investigativa busca simplemente coordinar acciones enmarcadas en una revisión bibliográfica con el fin de complementar ideas previas relacionadas La ciencia de la biotecnología y sus aplicaciones a 


\section{La ciencia de la biotecnología y sus aplicaciones}

Vol. 3, núm. 3., (2019)

Ingrid Lissette Salas Hurtado; Gustavo Luis Campi Rivera; Margarita Cristina Guillén Macías; Jazmín Denise Menéndez Posligua

través de una revisión de literatura, para así finalmente elaborar un cuerpo de consideraciones generales que ayuden a ampliar el interés propuesto.

\section{Tipo de Investigación}

Dentro de toda práctica investigativa, se precisan acciones de carácter metodológico mediante las cuales, se logra conocer y proyectar los eventos posibles que la determinan, así como las características que hacen del acto científico un proceso interactivo ajustado a una realidad posible de ser interpretada. En este sentido, se puede decir, que la presente investigación corresponde al tipo documental, definido por Castro (2016), "se ocupa del estudio de problemas planteados a nivel teórico, la información requerida para abordarlos se encuentra básicamente en materiales impresos, audiovisuales y /o electrónicos”. (p.41).

En consideración a esta definición, la orientación metodológica permitió la oportunidad de cumplir con una serie de actividades inherentes a la revisión y lectura de diversos documentos donde se encontraron ideas explicitas relacionadas con los tópicos encargados de identificar a cada característica insertada en el estudio. Por lo tanto, se realizaron continuas interpretaciones con el claro propósito de revisar aquellas apreciaciones o investigaciones propuestas por diferentes investigadores relacionadas con el tema de interés, para luego dar la respectiva argumentación a los planteamientos, en función a las necesidades encontradas en la indagación.

\section{Fuentes Documentales}

El análisis correspondiente a las características que predomina en el tema seleccionado, llevan a incluir diferentes fuentes documentales encargadas de darle el respectivo apoyo y en ese 


\section{La ciencia de la biotecnología y sus aplicaciones}

Vol. 3, núm. 3., (2019)

Ingrid Lissette Salas Hurtado; Gustavo Luis Campi Rivera; Margarita Cristina Guillén Macías; Jazmín Denise Menéndez Posligua

sentido cumplir con la valoración de los hechos a fin de generar nuevos criterios que sirven de referencia a otros procesos investigativos. Para (CASTRO, 2016) las fuentes documentales incorporadas en la investigación documental o bibliográfica, "representa la suma de materiales sistemáticos que son revisados en forma rigurosa y profunda para llegar a un análisis del fenómeno". (p.41). Por lo tanto, se procedió a cumplir con la realización de una lectura previa determinada para encontrar aquellos aspectos estrechamente vinculados con el tema, con el fin de explicar mediante un desarrollo las respectivas apreciaciones generales de importancia.

\section{Técnicas para la recolección de la información}

La conducción de la investigación para ser realizada en función a las particularidades que determinan a los estudios documentales, tiene como fin el desarrollo de un conjunto de acciones encargadas de llevar a la selección de técnicas estrechamente vinculadas con las características del estudio. En tal sentido, (Bolívar, 2015), refiere, que es "una técnica particular para aportar ayuda a los procedimientos de selección de las ideas primarias y secundarias”. (p. 71).

Por ello, se procedió a la utilización del subrayado, resúmenes, fichaje, como parte básica para la revisión y selección de los documentos que presentan el contenido teórico. Es decir, que mediante la aplicación de estas técnicas se pudo llegar a recoger informaciones en cuanto a la revisión bibliográfica de los diversos elementos encargados de orientar el proceso de investigación. Tal como lo expresa, (Bolívar, 2015) "las técnicas documentales proporcionan las herramientas esenciales y determinantes para responder a los objetivos formulados y llegar a resultados efectivos" (p. 58). Es decir, para responder con eficiencia a las necesidades investigativas, se introdujeron como técnica de recolección el método inductivo, que hizo posible 


\section{La ciencia de la biotecnología y sus aplicaciones}

Vol. 3, núm. 3., (2019)

Ingrid Lissette Salas Hurtado; Gustavo Luis Campi Rivera; Margarita Cristina Guillén Macías; Jazmín Denise Menéndez Posligua

llevar a cabo una valoración de los hechos de forma particular para llegar a la explicación desde una visión general.

Asimismo, se emplearon las técnicas de análisis de información para la realización de la investigación que fue ejecutada bajo la dinámica de aplicar diversos elementos encargados de determinar el camino a recorrer por el estudio, según, (Bolívar, 2015) las técnicas de procesamiento de datos en los estudios documentales "son las encargadas de ofrecer al investigador la visión o pasos que debe cumplir durante su ejercicio, cada una de ellas debe estar en correspondencia con el nivel a emplear" (p. 123). Esto indica, que para llevar a cabo el procesamiento de los datos obtenidos una vez aplicado las técnicas seleccionadas, tales como: fichas de resumen, textual, registros descriptivos entre otros, los mismos se deben ajustar al nivel que ha sido seleccionado.

\section{Resultados.}

Todos los organismos se componen de células que están programados por el mismo material genético básico, llamado ADN (ácido desoxirribonucleico). Cada unidad de ADN se compone de una combinación de los siguientes nucleótidos adenina (A), guanina $(\mathrm{G})$, timina $(\mathrm{T})$ y citosina (D), así como azúcar y fosfato. Estos nucleótidos se emparejan en hebras que se retuercen juntos en una estructura en espiral llamada "doble hélice", esta doble hélice es el ADN.

Cuando las células se reproducen, las cadenas de ADN de la doble hélice se separan debido a que el nucleótido siempre se empareja con T, y G siempre se empareja con C, cada hebra de ADN sirve como un modelo preciso para una proteína específica, excepto por mutaciones o errores en el proceso de replicación, una sola celda está equipada con la 


\section{La ciencia de la biotecnología y sus aplicaciones}

Vol. 3, núm. 3., (2019)

Ingrid Lissette Salas Hurtado; Gustavo Luis Campi Rivera; Margarita Cristina Guillén Macías; Jazmín Denise Menéndez Posligua

información de replicar en millones de células idénticas. Debido a que todos los organismos están formados por el mismo tipo de material genético (nucleótidos A, T, G y C), los biotecnólogos usan enzimas para cortar y retirar segmentos de ADN de un organismo y recombinar con $\mathrm{ADN}$ en otro organismo. Esto se conoce como tecnología de ADN recombinante (ADNr), y es una de las herramientas básicas de la biotecnología moderna. (Guia de la Biotecnologia, 2011)

La tecnología del ADNr es la manipulación de laboratorio de $\mathrm{ADN}$ en el que el ADN, o fragmentos de $\mathrm{ADN}$ de diferentes fuentes, se cortan y se recombinan utilizando enzimas. A continuación se inserta este ADN recombinante en un organismo vivo. La tecnología del ADN recombinante generalmente se utiliza como sinónimo de la ingeniería genética, permitiendo a los investigadores mover la información genética entre organismos no relacionados para producir productos o características deseadas o para eliminar características indeseables. (Guia de la Biotecnologia, 2011)

La ingeniería genética es la técnica de eliminar, modificar o añadir genes a una molécula de ADN con el fin de cambiar la información que contiene. Cambiando esta información, la ingeniería genética cambia el tipo o la cantidad de proteínas que un organismo es capaz de producir. Esta ingeniería se usa en la producción de fármacos, la terapia génica humana, y el desarrollo de plantas mejoradas (Subero, 2015). Por ejemplo, un gen de protección contra los insectos se ha insertado en varios cultivos maíz, algodón y patatas para dar a los agricultores nuevas herramientas para la gestión integrada de plagas. El maíz es resistente al barrenador europeo del maíz. Esta resistencia inherente reduce así el uso de pesticidas para el control de 


\section{La ciencia de la biotecnología y sus aplicaciones}

Vol. 3, núm. 3., (2019)

Ingrid Lissette Salas Hurtado; Gustavo Luis Campi Rivera; Margarita Cristina Guillén Macías; Jazmín Denise Menéndez Posligua

barrenador europeo del maíz, y a su vez requiere menos productos químicos que potencialmente proporciona mayor rendimiento en la biotecnología agrícola.

\section{La biotecnología industrial}

La biotecnología industrial aplica las técnicas de la biología molecular moderna para mejorar la eficiencia y reducir los impactos ambientales de los procesos industriales como el textil, papel y pulpa, y la fabricación de productos químicos. Por ejemplo, las empresas de biotecnología industrial desarrollar biocatalizadores, tales como enzimas, para sintetizar sustancias químicas. Las enzimas son proteínas producidas por todos los organismos.

En el uso de la biotecnología, la enzima deseada se puede fabricar en cantidades comerciales como productos químicos básicos (por ejemplo, acrilamida de calidad para polímeros) y estos productos químicos especializados se pueden producir usando aplicaciones biotecnológicas. La síntesis química tradicional implica grandes cantidades de energía y de los productos a menudo indeseables, tales como $\mathrm{HCl}$, con el uso de biocatalizadores, los mismos productos químicos se pueden producir de forma más económica y más respetuosa del medio ambiente. Un ejemplo podría ser la sustitución de la proteasa en los detergentes para otros compuestos de limpieza, las proteasas de detergente, que eliminan las impurezas de proteínas, son componentes esenciales de detergentes modernos. Se utilizan para romper las proteínas, el almidón y los ácidos grasos presentes en los artículos que se lavan. La biotecnología también se utiliza en la industria textil para el acabado de tejidos y prendas de vestir. (Guia de la Biotecnologia, 2011) 


\section{La ciencia de la biotecnología y sus aplicaciones}

Vol. 3, núm. 3., (2019)

Ingrid Lissette Salas Hurtado; Gustavo Luis Campi Rivera; Margarita Cristina Guillén Macías; Jazmín Denise Menéndez Posligua

Algunos cultivos agrícolas, tales como maíz, se pueden utilizar en lugar de petróleo para producir productos químicos. El azúcar de la cosecha puede ser fermentada a ácido, que se puede utilizar entonces como un producto intermedio para producir otras materias primas químicas para diversos productos. Se ha proyectado que el $30 \%$ de las necesidades de productos químicos y combustibles del mundo podría ser suministrada por dichos recursos renovables en la primera mitad del próximo siglo. Se ha demostrado, a escala de prueba, que biopulpaje reduce la energía eléctrica necesaria para el proceso de fabricación de pasta de madera en un 30\%. (Guia de la Biotecnologia, 2011)

\section{Biotecnología ambiental}

La biotecnología ambiental se utiliza en el tratamiento de residuos y prevención de la contaminación puede limpiar de manera más eficiente a muchos desechos que los métodos convencionales y reducir considerablemente la dependencia de los métodos de eliminación con base en tierra.

Cada organismo ingiere nutrientes para vivir y produce subproductos como el resultado de diferentes organismos que necesitan diferentes tipos de nutrientes. Algunas bacterias se nutren de los componentes químicos de los productos de desecho. Los ingenieros ambientales usan la biorremediación de dos maneras básicas debido a que es la aplicación más amplia de la biotecnología ambiental, introduciendo nutrientes para estimular la actividad de las bacterias ya presentes en el suelo en un sitio de desechos, o añadiendo nuevas bacterias al suelo de este modo, las bacterias digieren los residuos en el lugar y lo convierten en subproductos inofensivos, 


\section{La ciencia de la biotecnología y sus aplicaciones}

Vol. 3, núm. 3., (2019)

Ingrid Lissette Salas Hurtado; Gustavo Luis Campi Rivera; Margarita Cristina Guillén Macías; Jazmín Denise Menéndez Posligua

luego las bacterias consumen los materiales de desecho, que se mueren o regresan a sus niveles de población normales en el medio ambiente. (Guia de la Biotecnologia, 2011)

La Biorremediación, es un área de creciente interés, a través de la aplicación de métodos biotecnológicos, biorreactores de enzimas se están desarrollando para pre-tratar algunos componentes de los residuos y desperdicios de comida industrial y permitir su eliminación, a través, del sistema de aguas residuales en lugar de mecanismos de eliminación de residuos sólidos. Los residuos también se pueden convertir en biocombustible para hacer funcionar los generadores. Los microbios pueden ser inducidos para producir las enzimas necesarias y convertir materiales de plantas y vegetales en bloques de construcción para plásticos biodegradables. (Duarte, 2010)

En algunos casos, los subproductos de los microorganismos contaminantes que combaten son útiles a sí mismos. Por ejemplo, el metano se puede derivar de una forma de bacteria que degrada licor de azufre, un producto de desecho de la fabricación de papel. Este metano se puede utilizar como combustible o en otros procesos industriales.

\section{Aplicaciones humanos}

Los métodos biotécnicos ahora se utilizan para producir muchas proteínas para otros fines especializados y farmacéuticos. Una cepa inofensiva de la bacteria Escherichia coli, dada una copia del gen de la insulina humana, puede producir insulina. A medida que estas células bacterianas de edad genéticamente modificada producen la insulina humana, pueden purificarse y utilizarse para tratar la diabetes en seres humanos. Los microorganismos también pueden ser modificados para producir las enzimas digestivas. En el futuro, estos microorganismos podrían 


\section{La ciencia de la biotecnología y sus aplicaciones}

Vol. 3, núm. 3., (2019)

Ingrid Lissette Salas Hurtado; Gustavo Luis Campi Rivera; Margarita Cristina Guillén Macías; Jazmín Denise Menéndez Posligua

ser colonizados en el tracto intestinal de las personas con insuficiencias de enzimas digestivas. (Duarte, 2010)

Los productos de la biotecnología moderna incluyen los vasos sanguíneos artificiales de los tubos de colágeno recubiertas con una capa de la heparina anticoagulante (12). La terapia génica se basa en alterar el ADN dentro de las células en un organismo para tratar o curar una enfermedad. Esta es una de las áreas más prometedoras de la investigación biotecnológica. Nuevas terapias genéticas se están desarrollando para tratar enfermedades tales como la fibrosis quística, SIDA y el cáncer. (Cardenas, 2013)

Otra de las aplicaciones en seres humanos es para determinar la huella de ADN es el proceso de búsqueda en investigaciones criminales. El ADN de muestras de pelo, fluidos corporales o de la piel en una escena del crimen se comparan con los obtenidos de los sospechosos. En la práctica, se ha convertido en una de las aplicaciones más potentes y ampliamente conocidos de la biotecnología en la actualidad.

En otro proceso, la reacción en cadena de la polimerasa (PCR), también está siendo utilizado para identificar más rápidamente y con precisión la presencia de infecciones como el SIDA, la enfermedad de Lyme y Chlamydia donde estudios determinaron que la paternidad es una de las causas de contagio debido a que el patrón de ADN de un niño se hereda, la mitad de la madre y la otra mitad del padre. Para establecer la paternidad, se comparan las huellas dactilares de ADN de la madre, el niño y el supuesto padre. Las secuencias coincidentes de la madre y el niño son eliminados de la huella dactilar de ADN del niño; lo que queda viene del padre 


\section{La ciencia de la biotecnología y sus aplicaciones}

Vol. 3, núm. 3., (2019)

Ingrid Lissette Salas Hurtado; Gustavo Luis Campi Rivera; Margarita Cristina Guillén Macías; Jazmín Denise Menéndez Posligua

biológico. Estos segmentos se comparan entonces para una coincidencia con la huella digital de ADN del supuesto padre. (Cardenas, 2013)

Las pruebas de ADN también se utiliza en fósiles humanos para determinar cómo de cerca muestras fósiles relacionados son de diferentes ubicaciones geográficas y áreas geológicos. Los resultados arrojan luz sobre la historia de la evolución humana y la manera en que los ancestros humanos se establecieron diferentes partes del mundo. (Guia de la Biotecnologia, 2011)

Biotecnología para el siglo 21

Expertos en Estados Unidos anticipan que la población mundial en el año 2050 sea de aproximadamente $8,7 \mathrm{~mm}$ de personas. La población mundial está creciendo, pero su superficie no, y la mayor parte de las tierras de cultivo ideales de la tierra ya se está utilizando. Para evitar daños en zonas ambientalmente sensibles, como las selvas tropicales, se necesita aumentar el rendimiento de los cultivos de tierras actualmente en uso. El aumento de rendimiento de los cultivos, se logra a través del uso de la biotecnología y la constante necesidad de despejar más tierra para el cultivo de alimentos se reduce.

Los países de Asia, África y otros países están tratando de resolver cómo continuar alimentando a una población creciente. También están tratando de beneficiarse más de sus recursos existentes. La biotecnología es la clave para aumentar el rendimiento de los cultivos básicos, permitiendo a los agricultores cosechar mayores cosechas de tierras actualmente cultivadas, preservando al mismo tiempo la capacidad de la tierra para apoyar la agricultura continua. (Miranda, 2009) 


\section{La ciencia de la biotecnología y sus aplicaciones}

Vol. 3, núm. 3., (2019)

Ingrid Lissette Salas Hurtado; Gustavo Luis Campi Rivera; Margarita Cristina Guillén Macías; Jazmín Denise Menéndez Posligua

La desnutrición en los países subdesarrollados también se combate con la biotecnología. La Fundación Rockefeller patrocina la investigación sobre el "arroz dorado", un cultivo diseñado para mejorar la nutrición en el mundo en desarrollo. Los productores de arroz están utilizando la biotecnología para construir la vitamina A en el arroz, ya que, la deficiencia de la vitamina A es un problema común en los países pobres. Una segunda fase del proyecto aumentará el contenido de hierro en el arroz para combatir la anemia, que es un problema muy extendido entre las mujeres y los niños en los países subdesarrollados. (Miranda, 2009)

Las iniciativas similares utilizando la manipulación genética están orientadas a lograr cultivos más productivos mediante la reducción de su dependencia de los pesticidas, fertilizantes y riego, o aumentando su resistencia a enfermedades de las plantas. (Miller, 2009)

\section{Políticas Internacionales de la Biotecnología}

Los gobiernos nacionales y los organismos internacionales de formulación de políticas se basan en los científicos de alimentos y otros para desarrollar innovaciones que crearán productos alimenticios comercializables para aumentar el suministro de alimentos. Los gobiernos también se basan en la investigación científica, ya que, son responsables de establecer las normas de salud y seguridad con respecto a los nuevos desarrollos. Las organizaciones internacionales pueden sugerir enfoques de política y ayudar a desarrollar los tratados internacionales que estén ratificados por los gobiernos nacionales.

El éxito económico en el competitivo mercado internacional exige que la producción de alimentos sea más eficiente y rentable. Los gobiernos y las organizaciones internacionales apoyan la biotecnología de alimentos como un medio para evitar la escasez de alimentos a nivel 


\section{La ciencia de la biotecnología y sus aplicaciones}

Vol. 3, núm. 3., (2019)

Ingrid Lissette Salas Hurtado; Gustavo Luis Campi Rivera; Margarita Cristina Guillén Macías; Jazmín Denise Menéndez Posligua

mundial. Muchos organismos de formulación de políticas también están tratando de equilibrar el apoyo de la industria de la biotecnología alimentaria con llamados públicos para su regulación. Tales regulaciones son necesarias para proteger la salud y la seguridad pública, para promover el comercio internacional, la conservación de los recursos naturales, y dar cuenta de los problemas éticos. (Lacruz, 2007)

La mayoría de los alimentos procesados en el mercado contienen soja o maíz ingredientes que provienen de plantas modificadas genéticamente. Hasta la fecha ninguno ha planteado un riesgo para la seguridad alimentaria. Las principales preocupaciones de seguridad son el potencial de alterar el contenido de nutrientes o introducir alérgenos. (Duarte, 2010)

\section{Conclusiones.}

Durante el desarrollo de la investigación se observó que la biotecnología ha dado a los seres humanos varios productos útiles utilizando microbios, plantas, animales y su maquinaria metabólica recombinante. La tecnología de $\mathrm{ADN}$ ha hecho posible la ingeniería genética de microbios, plantas y animales que tienen capacidades novedosas.

Genéticamente se han creado organismos modificados utilizando métodos distintos de métodos naturales para transferir uno o más genes de un organismo a otro, generalmente utilizando técnicas como el ADN recombinante de tecnología. Las plantas modificadas genéticamente han sido útiles para aumentar el rendimiento de los cultivos y reducir la poscosecha. También se observó, que existen varias plantas de cultivo con valor nutricional mejorado de los alimentos lo que ha logrado la reducción de la dependencia de pesticidas químicos (cultivos resistentes a plagas). 


\section{La ciencia de la biotecnología y sus aplicaciones}

Vol. 3, núm. 3., (2019)

Ingrid Lissette Salas Hurtado; Gustavo Luis Campi Rivera; Margarita Cristina Guillén Macías; Jazmín Denise Menéndez Posligua

Los procesos tecnológicos del ADN recombinante han hecho inmensos impactos en el área de la salud al permitir la producción masiva de productos seguros y terapias más efectivas. Desde la terapéutica recombinante que son idénticas a las proteínas humanas, no inducen indeseables respuestas inmunológicas y están libres de riesgo de infección.

Otro de los casos mencionados en la investigación es la fabricación de la insulina humana a través de las bacterias, debido a que, su estructura es absolutamente idéntica a la de la molécula natural. La biotecnología es utilizada en enfermedades humanas, como cáncer, fibrosis quística, artritis reumatoide, Alzheimer, entre otras.

Finalmente se puede concluir, que el aumento de rendimiento de los cultivos, una mayor flexibilidad en ambientes de cultivo, un menor uso de pesticidas químicos y un mejor contenido nutricional, así como también, las aplicaciones en seres humanos para el tratado de enfermedades graves como la diabetes y el cáncer hacen que la biotecnología sea literalmente, el futuro del suministro mundial de alimentos y la de ciencia médica.

\section{Bibliografía.}

Bolívar, J. (2015). Investigación Documental. México. Pax.

Cardenas, L. (9 de Septiembre de 2013). Comunicados de prensa. Recuperado el 2019 de Julio de 2019, de http://www.nature.com/nbt/press_release/nbt1199.html

Castro, J. (2016). Técnicas Documentales. México. Limusa.

Davila, A. (2015). Diccionario de Términos Científicos. . Caracas: Editorial Oasis.

Duarte, S. (2010). Posición de la Asociación Dietética Americana: La biotecnología y el futuro de los alimentos. Revista de la American Dietetic Association , 20-30.

Guia de la Biotecnologia. (11 de Marzo de 2011). Recuperado el 2019 de Julio de 2019, de http://www.bio.org/aboutbio/guide1.html 


\section{La ciencia de la biotecnología y sus aplicaciones}

Vol. 3, núm. 3., (2019)

Ingrid Lissette Salas Hurtado; Gustavo Luis Campi Rivera; Margarita Cristina Guillén Macías; Jazmín Denise Menéndez Posligua

Horizons., C. N. (24 de Noviembre de 2018). Biotecnología para el siglo 21. Recuperado el 6 de Julio de 2019, de thttp://www.nal.usda.gov/bic/bio21

Lacruz, S. (4 de Diciembre de 2007). Política nacional e internacional de Decisiones en Biotecnología. Recuperado el 6 de Julio de 2019, de http://www.biotechknowledge.com/showlib.php3?194

Laya, L. (16 de Enero de 2016). Principios de la biotecnología. Recuperado el 5 de Julio de 2019, de http://www.nal.usda.gov/bic/Education_res/iastate.info/bio1.html

Miller, A. (2009). "La comida ... La gente que tendrían más que perder”,. New York Times , 1320.

Miranda, C. (23 de Octubre de 2009). Biotecnología Alimentaria-beneficios para los países en vías de desarrollo. Recuperado el 2019 de Julio de 6, de http://ificinfo.health.org/insight/janfeb99/foodbiotechnology.htm

Paña, A. (26 de Agosto de 2015). Backgrounder-Biotecnología Alimentaria. . Recuperado el 5 de Julio de 2019, de http://ificinfo.health.org/backgrnd/BKGR14.htm

Ramos, L. (2012). Aplicaciones de la biotecnología para Cultivos: Beneficios y riesgos. Consejo de Ciencia y Tecnología Agrícola: , 45-68.

Subero, R. (23 de Abril de 2015). Principios de la biotecnología. Recuperado el 2019 de Julio de 2019, de http://www.nal.usda.gov/bic/Education_res/iastate.info/bio1.html

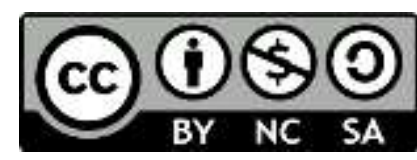

RECONOCIMIENTO-NOCOMERCIAL-COMPARTIRIGUAL

CC BY-NC-SA

ESTA LICENCIA PERMITE A OTROS ENTREMEZCLAR, AJUSTAR Y CONSTRUIR A PARTIR DE SU OBRA CON FINES NO

COMERCIALES, SIEMPRE Y CUANDO LE RECONOZCAN LA AUTORÍA Y SUS NUEVAS CREACIONES ESTÉN BAJO UNA LICENCIA CON LOS MISMOS TÉRMINOS. 